\title{
EDUCAÇÃO, EXÍLIO E REVOLUÇÃO: O CAMARADA PAULO FREIRE
}

\author{
DÉBORA MAZZA
}

Universidade Estadual de Campinas

NIMA IMACULADA SPIGOLON

Universidade Estadual de Campinas

RESUMO O artigo apresenta o percurso político-pedagógico de Paulo Freire, no exílio brasileiro (1964-1980), a partir de (auto)biografias. Autores sugerem que o exílio político promove diásporas, reconversões identitárias, militâncias e processos de mudança, nos percursos individuais e coletivos. Ancoradas em narrativas (auto)biográficas, incluindo uma entrevista jornalística concedida e coletada em África; as autoras do artigo esquadrinham tempos e espaços nos quais o então educador do governo do presidente João Goulart, em decorrência do golpe de 1964 e na condição de exilado político, aliou sua experiência de Educação com Revolução, impulsionado pelos desafios da Alfabetização de Adultos. Paulo Freire e família residiram e trabalharam nas Américas e na Europa e estenderam suas intervenções em África - nos países recém-independentes da colonização portuguesa. Em época de desmonte do Estado de direito e de inflexão social conversadora, recobrar o percurso de Paulo Freire no exilio e compreender os processos que transformaram o educador popular, que compunha os quadros do governo federal, em camarada revolucionário, é uma forma de se indignar contra as muitas formas de opressão e resistir dentro dos limites da ordem democrática.

Palavras-chave: Paulo Freire. Educação. Exílio. Revolução.

\section{ABSTRACT EDUCATION, EXILE AND REVOLUTION: THE CAMRADE PAULO FREIRE}

The article aims to explore the influence of exile in Paulo Freire's political activism in the domain of Adults Literacy. It aims at understanding how the condition of being exiled transform Freire's personal position, from a statesman into a revolutionary. The article draws from (auto) biographic writings produced during the exile Freire lived with his family after the coup d'Etat in Brazil in 1964, 
when he was forbidden to develop his projects in the country. The authors believe that such analysis it is paramount to bring Freire's contribution to pedagogical thinking into light as an attitude of resistance against the rise of extreme conservative political movements in Brazil.

Keywords: Paulo Freire. Education. Exile. Revolution.

\section{RÉSUMÉ ÉDUCACION, EXIL ET RÉVOLUTION: LE CAMARADE PAULO FREIRE}

L'article vise à explorer à quel point la condition d`être exilée a été important pour transformer Paulo Freire en un activist politique en ce qui concerne les défis de l'alphabétisation des adultes. Il vise à comprendre l'importance de l'exil pour transformer la position personnelle de Freire, d'homme d'Etat en révolutionnaire. L'article se compose d'un récit basé sur des écrits (auto)biographiques sur l'exil que Freire a vécu avec sa famille après le coup d'Etat au Brésil en 1964, quand on lui a interdit de développer ses projets d'alphabétisation des adultes dans le pays. Les auteurs croient qu'il est primordial de mettre en lumière la contribution de Freire à la pensée pédagogique comme une attitude de résistance contre la contemporain montée des mouvements politiques conservateurs extrémiste au Brésil.

Mots-clés: Paulo Freire. Education. Exil. Révolution.

\section{Paulo Freire em retrospectiva}

Não há outro caminho senão o da prática de uma pedagogia humanizadora, em que a liderança revolucionária, em lugar de se sobrepor aos oprimidos e continuar mantendo-os como quase 'coisas', com eles estabelece uma relação dialógica permanente. (FREIRE, 1972, p. 63)

Paulo Freire é conhecido nos cenários nacional e internacional como uma referência da Educação. 0 artigo persegue o exílio de Paulo e sua família, em decorrência da ditadura brasileira instaurada com o golpe de 1964, traça os percursos de sua vida e as repercussões dessa migração forçada, em sua obra, seguindo indícios (auto)biográficos.

No Brasil e na América Latina, as décadas 1960 e 1970 são marcadas por acontecimentos políticos, sociais e econômicos golpeados por ditaduras de caráter civil-militar que provocaram rupturas em projetos desenvolvimentistas (BOITO JR; BERRINGER, 2013). Isto alterou, de forma significativa, a realidade de pessoas e países.

O desenrolar desses acontecimentos estimulam a reflexão sobre a sociedade brasileira e a discussão de itinerários de sujeitos acometidos pelas ditaduras, que cercearam direitos econômicos, políticos e sociais, produzindo violência, autoritarismo e perseguição.

Procuramos, no conjunto da obra de Paulo Freire, as narrativas (auto)biográficas entendendo-as como um material que carreia conteúdos históricos e espelha certa visão de mundo, individual e coletiva (HALBWACHS, 2015). 
As narrativas não se caracterizam por um gênero puro, mas por pluralidades discursivas que entretêm relações diretas com a dimensão temporal da existência e da experiência humana. Elas são instrumentos de formação e lugares por meio dos quais os indivíduos tomam forma e elaboram a experiência vivida (DELORY-MOMBERGER, 2012).

Em sociedades letradas, as narrativas não se ancoram apenas nos recursos da memória e da oralidade e sim recorrem a referências variadas, manejadas pelo narrador, tais como: livros, publicações governamentais, jornais, debates públicos, mídia televisiva etc. Nesse enfoque, a (auto)biografia não é apenas auto e a oralidade não é apenas oral (CRUIKSHANK, 1996).

Assim, o conhecimento produzido pelos sujeitos através da narrativa nos permite verificar as possibilidades das escolhas conscientes, os constrangimentos dos sistemas normativos e as margens de negociação e ação (CHARTIER, 1996). Tais exercícios, por um lado, contribuem para a reflexividade dos sujeitos, tendo como foco a produção de um conhecimento relacional, contextualizado e informado pelas ações e opções dos pesquisados e pesquisadores e, por outro, incorporam um conjunto de questões éticas e políticas não restritas à lógica científica (DAVIS; PRADILLA, 2003).

As narrativas (auto)biográficas como um processo de (re)construção do eu individual e coletivo têm potencializado as pesquisas, na área das Ciências Humanas e Sociais, que se ocupam da Educação. Elas promovem uma redução da escala de observação, permitindo captar aspectos não visíveis desde uma perspectiva mais geral (DEMARTINI, 2005; NÓVOA, 2017; SOUZA; CASTAÑEDA; MORALES, 2014).

A micro-história urdida pelas narrativas permite capturar:

[...] en especial, las contradicciones, intersticios y fisuras por las que los seres humanos operan en el seno de sistemas prescriptivos y normativos, adaptándolos a su mentalidad y necesidades, en un juego de relaciones reciprocas entre el reino de la liberdad y de la necesidad. (VIÑÃO, 2000, p. 11)

Ancoradas em indícios (auto)biográficos, destacamos Paulo no Nordeste, o casamento com Elza, em 1944, e por meio dela o seu encontro com a Educação; já em 1950, o trabalho no Serviço Social da Indústria (SESI), os Movimentos de Educação de Base (MEB) e Cultura Popular (MCP), os Círculos de Cultura e a Alfabetização de Adultos, em Recife e Angicos. Os espaços, a visibilidade e os resultados dessas experiências, em meados de 1960, o levam a Brasília para atuar no Plano Nacional de Alfabetização (PNA), a convite do Ministério da Educação (MEC), e, depois, ao exílio.

À época, Paulo ficou associado aos governos de Arraes e Goulart, ${ }^{2}$ e alcançou uma notoriedade que acometeu igualmente Elza e seus filhos, pois suas propostas despertavam interesses, conquistavam adeptos e formavam opiniões, de consenso ou controversas; suas experiências compunham as Reformas de Base.

O golpe ${ }^{3}$ de 1964 levou ao governo um bloco de poder ligado aos militares e instaurou

1 [...] em particular, as contradições, os interstícios e as fissuras pelas quais os seres humanos operam dentro de sistemas prescritivos e normativos, adaptando-os à sua mentalidade e necessidades, em um jogo de relações recíprocas entre o reino da liberdade e da necessidade. (VIÑÃO, 2000, p. 11)

2 Governo de Miguel Arraes no Estado de Pernambuco (1963/1964), na prefeitura do Recife (1960/1962) e no Governo de João Goulart - presidente da República (1961/1964).

3 Dreifuss (2008) considera que o golpe não constituiu "um mero reflexo da supremacia econômica, mas "o resultado de luta política empreendida pela vanguarda destes novos interesses". Com isso, designamos o golpe de 1964, como civil-militar, em decorrência da atuação de relevantes setores da sociedade, organizados em forma de blocos de poder, tais como: bloco econômico multinacional e associado, autoridades eclesiásticas, intelectuais e políticos de orientação liberal-conservadora, meios de comunicação e mídia, demonstrando ser necessário "conquistar o Estado". (DREIFUSS, 2008, p. 482) 
um Estado de exceção que conta com Atos Institucionais (Al); cassação de direitos políticos dos considerados subversivos ou perigosos; repressão aos movimentos populares e sociais; proibição de manifestações contrárias à ordem vigente; cerceamento aos meios de comunicação; censura aos artistas, intelectuais, estudantes e militantes; alinhamento ao imperialismo norte-americano; controle dos sindicatos; implantação do bipartidarismo, com oposição controlada; enfrentamento armado aos movimentos de guerrilha adversos ao governo vigente; uso de métodos violentos de punição, tortura, prisão, desaparecimentos; expulsão, exílio e banimento dos opositores e tidos como contrários à moral e à ordem pública estabelecida.

Sem condições de aprofundar, é importante analisar o golpe de 1964 como parte do processo histórico de transformações econômicas, políticas e sociais, em curso na sociedade brasileira (FERNANDES, 1975).

Paulo Freire e sua família, assim como outros, são diretamente afetados pelas injunções do processo histórico da ditadura e as consequências do exílio, que, para ele, perdurou por dezesseis anos. Paulo visita o Brasil em 1979, com o início da abertura política, e retorna definitivamente em 1980.

A retrospectiva do exílio de Paulo e família cobre o período de 1964 a 1979 e, segundo a perspectiva (auto)biográfica, recorta, das narrativas, os atos significativos de onde emergem valorações, compreensões de mundo, percepções de existência, atitudes, recordações e desejos passiveis de interpretações tanto pelo sujeito que narra quanto pelo pesquisador que busca compreender a vida individual e coletiva em suas variadas nuanças (BRUNER, 1997).

Essa perspectiva também permite tomar algumas histórias pessoais como histórias exemplares, que se vinculam a um conjunto de outras histórias vividas, ouvidas e construídas.
Elas participam de redes de fatos e comunicações por meio das quais se produzem, interpretam e medeiam muitas outras histórias.

Sua importância cultural e moral está no modo como capturam e abrem novas possibilidades de existir. [...] são aquelas em relação as quais somos compelidos a pensar não para imitá-las [...] mas porque se convertem em depósitos de determinados tempos e espaços. (LARROSA, 1996, p. 473-474)

Assim tecemos a urdidura desse artigo.

\section{Golpe de 1964: início do exílio}

Quando o golpe se definiu, do ponto de vista da tomada de poder, eu estava em Brasília. Foi exatamente no dia 1ㅇ de abril de 1964. E resolvemos, Elza e eu, que os filhos, então conosco, voltariam para o Recife com a minha mãe. E Elza preferiu ficar comigo para a gente decidir ainda o que é que eu faria. (FREIRE; GUIMARÃES, 2001, p. 35)

O exílio brasileiro foi consequência do aparato utilizado pelos militares para manteremse no poder, no período de 1964/85, e atingiu homens e mulheres, sozinhos e acompanhados, adultos e crianças, que saíram do país em virtude de se tornarem alvo da ditadura. Dentre eles Paulo, Elza e seus filhos: Madalena, Cristina, Fátima, Joaquim e Lutgardes.

O golpe de 1964 depõe o presidente João Goulart e os grupos a ele vinculados e leva certa utopia ${ }^{4}$ ao cárcere. 0 exílio define-se antes de deixar o país, pois "quando um homem necessita de se esconder é porque perdeu a liberdade!" (JULIÃO, 1978, p. 289) Ações, permanências e vidas em solo brasileiro são afetadas, em uma demonstração do poder arbitrário e abusivo, que persegue, expulsa e exila. A família Freire soma-se ao contingente de brasileiros exilados.

4 Operamos com o conceito de utopia como parte da realidade, já que é a partir do que se vive que sonhos e esperanças de um futuro melhor são projetados, sendo tecidos nos movimentos possiveis de transformação (FREIRE, 2000; GALEANO, 2007; LEFEBVRE, 2008; PEPETELA, 1997; VÁZQUEZ, 2001). 
Numa rápida recapitulação, havia vivido intensamente no Brasil, precisamente no Recife, uma experiência rica enquanto educador, primeiro como professor de Língua Portuguesa, depois como professor de História e Filosofia da Educação da Universidade do Recife, a que juntei configura uma atividade permanente ora em áreas urbanas, ora em áreas rurais, às vezes como educador popular, desde os começos dos anos 40. Nos anos 60 participara, com minha geração, de um momento desafiador da história político social do país [...] Antes do golpe de Estado de 1964, coordenara o Plano Nacional de Alfabetização do Ministério da Educação. Com o golpe, que pôs por terra os sonhos da minha geração, parto para o exílio. (FREIRE; FAUNDEZ, 1985, p. 114)

O exílio, tal como descrito acima, é um mecanismo de exclusão política, e de terrorismo de Estado, que desenvolve papel fundamental nas configurações das relações nacionais, latino-americanas e mundiais (COSTA et al, 1980; YANKELEVICH, 2007).

Paulo narra:

Um dos problemas fundamentais do exilado ou da exilada está exatamente em como resolver a tensão aguda entre o transplante de que é vítima e o necessário implante, que nem pode estar além nem aquém de certos limites. Se se enraíza demasiado na nova realidade, corre o risco de renunciar a suas raízes; se fica na pura superficialidade da realidade nova, corre o risco de se aniquilar numa nostalgia de que dificilmente se libertará. Experimentei a ambiguidade de estar e não estar [...] mas cresci na dramaticidade da experiência. (FREIRE; FAUNDEZ, 1985, p. 13)

No Brasil, o importante a destacar nessa fase é a mobilização educacional e cultural, que refletia uma perspectiva socio-histórica crítica. Entre 1950 e 1960, estudantes, intelectuais, políticos e militantes, clérigos e militares desenvolveram um movimento que visava despertar nas massas o senso de consciência do seu potencial, a fim de prepará-las como participantes e beneficiárias da mudança social (TOLEDO, 1983; WEFFORT, 1978).
Estas décadas engendram um conflito irremediável, que se traduziu nas contradições criadas pela radicalização e a polarização de forças oriundas da tomada de consciência sobre os limites do projeto nacional-desenvolvimentista que, se alinhando à economia capitalista internacional, explorava e submetia de maneira desigual e combinada as especificidades regionais, objetivando o fortalecimento do mercado nacional; e o projeto modernizador, que colocou em marcha um modelo financiado pelo capital internacional que cobrava o alinhamento do Brasil ao imperialismo norte-americano. As forças de esquerda assumiram a defesa da nacionalização do modelo econômico. As forças de direita saíram em defesa da interdependência ao imperialismo, assegurada pela doutrina de segurança nacional. O golpe de 1964 representou a vitória da segunda opção (MAZZA, 2003, p. 64-67).

Dois fatores coadunam com a conjuntura e o impulso dado ao trabalho de Paulo Freire, no início dos anos de 1960, o primeiro, deve-se à consciência da gravidade do analfabetismo no Brasil e à ineficácia das campanhas que mantinham mais de $50 \%$ da população maior de 14 anos não alfabetizada, ocasionando críticas que apontavam a necessidade de diretrizes para a educação de adultos, equacionando-a a uma sociedade em transformação (PAIVA, 1973, p. 207); o segundo, ao engajamento de toda uma geração que se lançou no plano sociocultural através de ações educativas com forte conteúdo político-ideológico (FREIRE, 1967).

Em face disso, entre o auge do populismo, a crise de hegemonia política e a aceleração da economia, identificam-se as repercussões dos movimentos mais expressivos de Educação, Educação Popular e Cultura Popular do Brasil (FÁVERO, 1983; BEISIEGEL, 1982). Era necessário acertar ponteiros políticos e sociais com as conquistas econômicas. Tornar lugar comum e de prioridade a convicção de que o desenvol- 
vimento econômico, político e social do Brasil dependia de planos e ações de construção educacional, através de um pacto popular.

Tal construção educacional contava com as propostas de Paulo Freire, que assumem dimensões nas esferas governamentais da época, do Estado de Pernambuco e depois do Planalto Central, quando o levam para o Ministério da Educação - MEC - com Darcy Ribeiro, e o Plano Nacional de Alfabetização - PNA - com Paulo de Tarso Santos, tomando-o como referência nacional da Alfabetização de Adultos.

o trabalho educativo desenvolvido por Paulo Freire e sua equipe, junto aos adultos analfabetos ou semialfabetizados, compreendia: 1) investigar suas condições de vida e a linguagem cotidiana utilizada; 2) levantar o universo vocabular; 3) extrair as palavras geradoras; 4) elencar a riqueza silábica e o conteúdo existencial das palavras geradoras para os educandos; 5) organizar as fichas de cultura (slides, iconografias ou cartazes) com representações de cenas do mundo da natureza e do mundo da cultura; 6) alimentar os círculos de cultura com diálogos entre educadores-educandos potencializados pela reflexão da pessoa humana como criadora de cultura na relação com a natureza. Os objetivos desse trabalho eram: 1- conscientização, 2- alfabetização e 3- pós alfabetização. 0 domínio das técnicas de leitura e escrita era o meio e não o fim do trabalho educativo. A educação conscientizadora era condição para a realização de um projeto de sociedade urbano-industrial, compromissada com seu povo, democrática e menos injusta.

Essa oficialização do trabalho de Paulo Freire representava a incorporação, a nível ministerial, da orientação de atividades ligadas à Educação de Adultos, desenvolvidas inicialmente no Nordeste, o que gerou inquietações a ponto do PNA ser suspenso em 02 de abril de 1964 e extinto em 14 de abril pelo decreto no
53.886, como um dos primeiros atos da ditadura. A rapidez nessa deliberação sugere o perigo que representava para o novo governo a proposta que Paulo e Elza elaboraram e implementaram (BEISIEGEL, 1974; SPIGOLON, 2016).

Paulo Freire é atingido como integrante do staff governamental, pois se vinculava oficialmente ao presidente João Goulart, que operava dentro da ordem, por meio de instituições consolidadas do regime democrático, fazia parte dos "intelectuais de Estado" e pertenceu à primeira leva de exilados brasileiros da geração de $1964 .^{5}$

No burburinho dessas experiências, dá-se a equalização de fatos que vão conduzi-lo ao exílio. Cabem indagações: em que medida ele e sua família foram atingidos pela ditadura? Que impactos a condição de exilado provocou na sua vida e no seu trabalho? Que injunções o exílio produziu na configuração familiar? Como o exílio mudou sua condição social de educador de governo para a de político subversivo? Como o estatuto de exilado empurrou os Freires para além dos limites locais, regionais e nacionais, e os inseriu nas esquerdas transnacionais?

As questões aqui anunciadas buscam dialogar com a pedagogia crítica e problematizadora que integra a proposta de trabalho de Paulo (FREIRE; FAUNDEZ, 1985).

\section{Ditaduras, utopias e sentimentos do exílio}

Somente nos meados de janeiro de 1965, nos encontramos de novo. Elza, as três filhas e os dois filhos, trazendo consigo também seus es-

5 Rollemberg (1999) aponta o exílio brasileiro como uma experiência de duas gerações, a de 1964 e a de 1968. A primeira, que começou a deixar o Brasil em 1964, se caracterizava pela atuação política através das vias legais, da vinculação aos movimentos reformistas e aos partidos existentes antes do golpe. A segunda saiu a partir de 1968 com o ciclo repressivo dos Atos Institucionais, vinculando-se a organizações clandestinas, ação revolucionária, militância em movimentos estudantis e luta armada. 
pantos, suas dúvidas, suas esperanças, seus medos, seus saberes feitos e fazendo-se recomeçaram comigo vida nova em terra estranha. (FREIRE, 1992, p. 36)

O exílio, sob os auspícios da ditadura, preconiza um período sombrio da história do Brasil e de países da América Latina. Em síntese, identificamos conjunturas nacionais e internacionais que, a par dos percursos de Paulo, nos permitem elaborar denúncias humanitárias, apontar processos de resistência democrática e identificar propostas político-pedagógicas.

Narra Paulo:

No momento em que deixamos o nosso contexto de origem e passamos para outro, a nossa experiência de cotidianeidade se faz mais dramática. Tudo nela nos provoca ou pode provocar. Os desafios se multiplicam. A tensão se instala. [...] no contexto original o exilado ou a exilada vivia imerso na sua cotidianeidade, que lhe era familiar, no contexto de empréstimo precisa, permanentemente, emergir da cotidianeidade, perguntando-se sobre ela. É como se estivesse sempre em vigília. (FREIRE; FAUNDEZ, 1985, p. 39)

As reflexões e inflexões das experiências de Paulo iniciadas no Brasil alentam as propostas político-pedagógicas durante o exílio.

Tentamos esquadrinhar, nos contornos das Américas, Europa e África(s), as lutas cotidianas de Paulo Freire, golpeadas por ditaduras, opressão e violências que informam acontecimentos na contradição entre o conformismo e a resistência (CHAUÍ, 1985).

As experiências de exílio levam Paulo a:

[...] repensar os dados concretos da realidade, sendo vivida, o pensamento profético, que é também utópico, implica a denúncia de como estamos vivendo e o anúncio de como poderíamos viver. É um pensamento esperançoso. É nesse sentido que [...] não apenas fala do que pode vir, mas, de como está sendo a realidade, denunciando-a e anunciando um mundo meIhor. (FREIRE, 2000, p. 118-119)
Assim, Paulo Freire deu continuidade às escrituras em torno da problemática da educação. Sob tal condição, o enfrentamento da vida e a busca de infraestrutura cotidiana significavam a própria sobrevivência e de sua família.

Vivi no Chile antes do governo Allende. Sai em 69 [...] e uma das coisas que aprendi, nessa reflexão sobre a cotidianeidade, era que as afirmações abstratas políticas, religiosas ou morais, que eram excelentes, não se transformavam, não se concretizavam nas ações individuais. Éramos revolucionários em abstrato, não na vida cotidiana [...] a revolução começa na revolução da vida cotidiana. (FREIRE; FAUNDEZ, 1985, p. 35)

Após 1964, Paulo Freire fundamentou sua proposta político-pedagógica, ampliou e aprofundou o entendimento face à radicalização do seu pensar.

\section{Américas, Europa e África: tempos e espaços no exílio}

'Velho, na verdade, a infra-estrutura desta família é a velha!' Quer dizer: 'Abre o olho, porque se arrebentar a infra-estrutura a gente se acaba...' Na verdade, a Elza sustentou grande parte [...] apesar de toda essa contribuição extraordinária da Elza, não é fácil viver o exílio [...] não era fácil para mim evitar um sentimento de culpa, porque todos estavam lá por minha causa. (FREIRE; BETTO, 2000, p. 90-91)

No exílio, Paulo e família movimentam-se por entre as Américas, Europa e África. Said (2003) sugere que o exílio marca a história da humanidade, com partidas e incertezas de retorno. Trata-se de um tempo e um espaço indeterminados.

As fronteiras para o exílio ampliam-se com a saída do Brasil, inicialmente via América do Sul, primeiro destino a receber muitos perseguidos pela ditadura brasileira que, de lá, passam a circular pelas Américas, Europa e outros continentes que explicitam as múltiplas saídas e chegadas, características das circulações 
diaspóricas que desenham espaços de vida (CORTES; FARET, 2009).

A necessidade de se adaptar a idiomas e climas, a luta pela sobrevivência, o espalhamento pelo mundo conduz a redefinições identitárias (DUBAR, 2009).

A resiliência ao desconhecido convive com o desafio permanente de resistir e manter as origens. As saudades do Brasil também se transformaram em:

[...] aprendizado que, repito, não é fácil, tem que ser vivido, por que o exílio o exige. Por causa de tudo isso, é que Elza e eu sempre nos esforçamos para que a nossa saudade do Brasil jamais se constituísse numa espécie de doença sentimentalista. Sentíamos fortemente a falta do pais, a falta do povo, a falta da cultura; [...] mas jamais permitimos que a falta que sentíamos disso tudo se transformasse numa nostalgia que nos empalidecesse, que nos fizesse tristonhos, sem descobrir razão de ser na vida. (FREIRE; FAUNDEZ, 1985, p. 32-33)

Nos exílios internos e externos (HALL, 2009), Paulo e família deslocam-se por territórios, ajuntam-se a apátridas, ampliam horizontes de trabalho, desenham contatos com outras culturas e esboçam inserções em tempos e espaços de educação, exílio e revolução.

A impossibilidade de retornar ao país de origem produz rupturas que implicam vínculos com e em outros territórios. A desterritorialização é acompanhada ou seguida por reterritorializações (BRUNEAU, 2009).

Até que ponto lutamos por criar ou encontrar caminhos em que, contribuindo de certa forma com algo, escapamos à monotonia de dias sem amanhã. Esta é uma das lições que o exílio pode ensinar, desde, porém, que o exilado se torne sujeito do aprendizado. [...]. O exílio é o exilado assumindo de forma crítica, a condição de exilado. (FREIRE; FAUNDEZ, 1985, p. 19-21)

Paulo Freire contrai-se e se expande, em um movimento produtivo que parteja obras que 0 tornam mundialmente conhecido. Das Améri- cas para a Europa e de lá para a(s) África(s). A vida e a obra de Paulo Freire foram se configurando em tempos e lugares, alguns que residiu - Américas: Brasil, Bolívia, Chile e Estados Unidos; Europa: Suiça; e outros em que se inseriu profissionalmente - África: Guiné-Bissau, Cabo Verde, Angola e São Tomé e Príncipe. Esta composição fomentou a construção do camarada.

Durante o exílio, Paulo Freire sistematiza sua proposta junto à Educação e, particularmente à de Adultos, com adaptações do que aconteceu no Brasil e incorporações do que foi realizando em muitos países, vinculado a instituições, organizações e partidos.

Em setembro de 1964, Paulo Freire sai do país. Vinte dias depois de chegar a La Paz, Bolívia, a fim de trabalhar no Ministério da Educação, o grupo de brasileiros, incluindo Paulo presenciam o governo do presidente Paz Estenssoro ser deposto, sob o golpe comandado pelo general René Barrientos. Com isso, o país deixava de ser uma porta de entrada para os exilados brasileiros e se tornava uma porta de saída para aqueles duplamente exilados, do Brasil e da Bolívia:

Foi um momento duro. Eu me lembro de que, em 10 de novembro de 1964, escrevendo para Elza - era aniversário do nosso casamento, lhe dizia não saber para onde ir. Só sabia que era impossivel continuar na Bolívia. Nessa carta falava do nosso querer bem, dos nossos filhos, filhas, mas não falava do momento de real angústia que estava vivendo. Não ia resolver nada mandar um pedaço da minha inquietação para a Elza [...] Foi aí que dois amigos Paulo de Tarso [Santos] e o Plínio [de Arruda Sampaio] começaram a tentar encontrar caminhos que me fizessem chegar ao Chile. Aliás, essa solidariedade humana e política sempre foi dada pelo Paulo de Tarso e pelo Plínio a todos os exilados políticos. (FREIRE; GUIMARÃES, 2001, p. 77)

A Bolívia é incluída no mapa das ditaduras latino-americanas da década de 1960. É o exílio reunindo exilados e países. 
Da Bolívia para o Chile, mais uma partida de Paulo, outro exílio e a Diáspora Freiriana (SPIGOLON, 2014) vai se constituindo, marcando as instabilidades em torno de quando, como, porque e para aonde ir.

A narrativa autobiográfica aponta cenários, situações, elos da memória e registros de acontecimentos históricos. Segundo Paulo:

[...] o salvo-conduto se queimou num incêndio durante o golpe na Bolívia. Depois do golpe, eu procurei as autoridades do Governo, para sair de lá para o Chile, e me comunicaram então que eu não existia [...] E eu disse para o coronel: 'Olha, coronel, o senhor me desculpe, mas eu não tenho nada a ver com o incêndio que houve aqui no golpe, a revolução é dos senhores. Agora faço um apelo para que o senhor aceite que eu sou Paulo Freire e, para ajudar o senhor, tenho uma carteira de identidade brasileira.' Foi o que me salvou. A Elza me pôs isso no bolso no dia da minha saída do Brasil (FREIRE; GUIMARÃES, 2001, p. 72)

Repetidas vezes, exilados políticos brasileiros da geração 1964 partiram pela fronteira, principalmente em direção ao Uruguai, à Bolívia e, em seguida, ao Chile, uma vez que não era preciso passaporte, a carteira de identidade era suficiente. Assim sucedeu com Paulo:

Tomamos um avião chileno de Arica a Santiago. No controle de passaporte, quando dei o salvo-conduto boliviano que conseguira através do que contei, o funcionário chileno me olhou e disse que, se eu era brasileiro, deveria ter uma identidade brasileira. A lembrança de Elza me salvou pela segunda vez, porque o funcionário disse que, se não a tivesse, seria obrigado a me botar no mesmo avião e me devolver a La Paz. (FREIRE; GUIMARÃES, 2001, p. 78)

No mesmo ano de 1964, Paulo Freire, após ser exilado no Brasil e, pela segunda vez, na Bolívia, chega ao Chile. À época da presidência de Eduardo Frei Montalva, do Partido da Democracia Cristã - PDC, sendo o primeiro democrata cristão chefe de Estado das Américas e que permanece até 1970, ou seja, ele foi presidente durante o período em que Paulo vai fazer parte, no Chile, do grupo de brasileiros exilados. Frei propôs uma "revolución en libertad".

Para muitos professores e intelectuais da geração 1964, que chegaram no Chile antes do governo Allende, foi possível se inserir socialmente e trabalhar, destacadamente, nos organismos de administração e planejamento do governo, e nos organismos internacionais geralmente filiados à ONU, cujo melhor exemplo é o da Comissão Econômica para a América Latina (CEPAL). No caso de Paulo Freire, o Instituto de Capacitação e Investigação em Reforma Agrária (ICIRA):

Cheguei e comecei a trabalhar imediatamente. 0 contexto do exílio até me deu possibilidade enorme de aprender mais e aprofundar as coisas que já vinha fazendo no Brasil [...] fui levado por Thiago de Mello e pelo Strauss ao gabinete de Jacques Chonchol, do Instituto de Desarrollo Agropecuário [...] saí do seu gabinete contratado [...] Ainda passei um bom tempo até dominar e entender o castelhano do Jacques; discutimos e comemos juntos, ora ele almoçando conosco a célebre galinha de cabidela que a Elza preparava, ora nós jantando com ele. (FREIRE; GUIMARÃES, 2001, p. 80-81)

Durante tais encontros, entremeados por discussões sob a ambiência latino-americana, Paulo ponderava:

[...] o fato de ser um exilado [...] a necessidade de me reintegrar tanto quanto possivel à prática já desenvolvida anteriormente no Brasil, superando-a e aprofundando as reflexões que iniciara [...] Além disso, tinha uma preocupação política de acertar. E de dar uma contribuição fora do meu país que, indiretamente, era também uma contribuição ao meu país [...]. (FREIRE; GUIMARÃES, 2001, p. 93-95)

Contribuições que se originaram na colônia de exilados brasileiros em Santiago, tendo em vista também a vida e a sobrevivência fora do país de origem. 
Tudo isso coincidiu com a convivência que pude ter com a equipe de brasileiros que na época estava no Chile [...] Fernando Henrique, Weffort, Ruth Cardoso, José Serra, Wilson Cantoni, Strauss, Jader, Flávio Toledo, Paulo de Tarso, Almino Affonso, Plínio Sampaio, Adão Ferreira Nunes, Ernani Fiori, Álvaro Vieira Pinto e Álvaro de Freitas [...] Thiago de Melo, Clodomir Morais, Jesus Soares Pereira [...]. (FREIRE; GUIMARÃES, 2001, p. 93-95)

Essas narrativas (auto)biográficas nos sugerem que o exílio de Paulo Freire, a partir do Chile, serviu de ruptura com os "paroquialismos" locais e constituiu uma abertura para a realidade latino-americana e mundial.

Depois dessas reuniões e seminários que dei, a Elza me sugeriu que eu passasse a escrever. A sugestão foi realmente dela. Eu comecei, e depois tomei certo gosto pela escrita. Foi a partir daí que escrevi e emendei a Pedagogia do Oprimido. (FREIRE; GUIMARÃES, 2001, p. 96)

Assim, os reflexos do "Método Paulo Freire" iniciados no Brasil e a expansão deste método, a partir do trabalho no ICIRA, marcam a sua narrativa acompanhada da realidade pernambucana, latino-americana, incluindo o início do exílio com o golpe de 1964 até a feitura do “Pedagogia do Oprimido", no outono de 1968, em Santiago do Chile.

Entre as décadas de 1960 e 1980, os golpes políticos aliados com às Forças Armadas insurgiram-se nos cenários políticos da América do Sul. Deles decorreram regimes militares e ditaduras instauradas no Brasil e na Bolívia, em 1964, no Chile e no Uruguai, em 1973, na Argentina, em 1976, e persistiram, no Paraguai, desde 1954.

Em 1969, Paulo Freire é compelido a deixar Santiago e seguir para Cambridge.

Sair do Chile, 'não abandonar o Chile, do ponto de vista do meu querer bem', já havia discutido com a Elza. A saída para os Estados Unidos foi uma decisão que envolveu toda a família. (ROSAS, 2003, p. 34)
As impermanências das chegadas consolidaram a permanência da condição de exilado político brasileiro, cortando o mapa das Américas: do Sul e do Norte, mantendo o foco do trabalho na educação e na alfabetização de adultos.

[...] a ida para os Estados Unidos foi uma espécie de grande desafio para mim, além de surpresas [...] inclusive em torno da política brasileira e do que estava acontecendo na área da alfabetização de adultos [...] O primeiro de todos, a própria decisão. Você acredita que quando me chegou o convite eu quis recusar? Ingênua e arrogantemente pensava nada ter a aprender e nada ter a ensinar na matriz do imperialismo. Elza, uma vez mais, marcou sua presença junto a mim. Comentando com ela a intenção, a decisão, quase de não ir, ouvi dela estas perguntas: 'Você acha, porventura, que toda a população dos Estados Unidos é imperialista? E onde anda a sua radicalidade? Virou sectário? Por que não aposta na outra parte que por pequena que seja não é imperialista e está lá também?' Aceitei o convite. Fui e não me arrependi de ter ido. (FREIRE; GUIMARÃES, 2001, p. 110)

Nos Estados Unidos, a convite da Universidade de Harvard, a produção de Paulo continua lá e a partir de lá. Então, conforme narrou:

Em 69 eu voltei e aí eu já era matéria do New York Times. Nessa altura eu já tinha o original de Pedagogia do Oprimido terminado, que só saiu em setembro de 70 [...]. Foi exatamente neste intervalo que fui convidado para Harvard [...]. Quando voltei ao Chile da primeira viagem, comecei a receber convites para os Estados Unidos. Foi uma coisa muito engraçada. Porque recebo a carta de Harvard e oito dias depois recebo a daqui do CMI. Harvard me propunha estar lá em abril de 69, e o Conselho me propunha estar aqui em setembro. Resolvemos fazer uma contraproposta aos dois. À Harvard para ficar até fins de 69 e ao Conselho para ir no começo de 70. Os dois aceitaram e foi bom, porque eu queria muito ter a experiência nos Estados Unidos. (FREIRE; GUIMARÃES, 2001, p. 108-109)

A perspectiva autobiográfica demarca as posições assumidas por Paulo Freire, no exílio, 
ante as circunstâncias. A travessia do Atlântico representava "a chegada na Europa, em Genebra [...] com a certeza de uma duração de tempo maior" (FREIRE; GUIMARÃES, 2002, p. 104).

Durante o exílio, alguns países promoveram fatores de atração e outros de repulsão, segundo as oportunidades de trabalho, os alinhamentos políticos, as condições de vida familiar e as redes relacionais. Essas variáveis influenciaram as escolhas de Paulo Freire, entre as Américas e a Europa:

[...] eu já tinha aprendido no Chile o que significa o exílio, enquanto ruptura, enquanto possibilidade ou tentativa de re-visão e de re-construção do próprio ser do exilado, envolvendo questões culturais, adequações, inadequações, frustrações, medos, inseguranças, saudades.... Tudo isso tinha provocado em mim necessariamente um aprendizado iniciado no Chile, que tinha continuado nos Estados Unidos. [...] Eu me dei à Europa com possibilidade de viver muito mais tempo lá. Realmente, vivi dez anos em Genebra. [...] o contexto de Genebra, que, pouco a pouco se prolonga, se estende ao resto do mundo, foi o contexto de uma grande, de uma enorme riqueza de aprendizado para mim. [...] deve ter havido uma série de momentos em que eu tive um espanto maior, mas os espantos são absolutamente fundamentais e necessários ao processo de conhecimento. (FREIRE; GUIMARÃES, 2002, p. 104-105)

A chegada na Europa representou a fase mais duradoura do exílio, envolvendo um aprendizado maior em torno do trabalho com os projetos de reconstrução nacional e a educação dos povos africanos.

$\mathrm{Na}$ Suiça, Paulo Freire trabalhou vinculado ao Conselho Mundial de Igrejas (CMI), na condição de exilado político brasileiro. Lá, em Genebra, não ficou rendido às burocracias do Departamento de Educação e, juntamente com a equipe do Instituto de Ação Cultural (IDAC), criou condições para desenvolver assessorias aos países africanos recém-libertos dos processos de colonização.

\section{Paulo continua:}

Nunca ninguém me perguntou, no Conselho Mundial, em dez anos, se eu era isso ou aquilo, do ponto de vista religioso. Nunca eu fui chamado pelo secretário geral - que era assim uma espécie de papa - para me dizer 'se acautele!' ou 'modere um pouco o seu discurso!', nada! Eu nunca talvez tenha sido tão livre, enquanto trabalhador, quanto fui lá. (FREIRE; GUIMARÃES, 2002, p. 104-105)

Por vários fatores, o IDAC ressignificou a luta e a sobrevivência, e mediatizou a inserção político-pedagógica e o:

[...] reconhecimento crítico da inviabilidade histórica de pensar, em curto prazo, numa reinserção no Brasil, que nos permitiu esperar, esperançosamente, por um outro momento histórico, mas não esperar de braços cruzados. Foi por isso que, agarrando as possibilidades de intervenção que o IDAC nos oferecia, nos entregamos a elas na Itália, na Suiç̧a, na Guiné-Bissau. (FREIRE; OLIVEIRA; CECCON, 1980, p. 11)

Durante o exílio e residindo na Suiça, houve a produção de Paulo Freire na Europa. Lá, Paulo ampliava suas redes relacionais e institucionais pelo mundo e, de forma mais significativa, junto aos países africanos que, ao lutarem para não continuar sendo colônias portuguesas, alavancaram processos de libertação nacional. Acompanhou, em África, a convite do Partido Africano para Independência de Guiné Bissau e Cabo Verde (PAIGC) e das Forças Armadas Revolucionárias do Povo (FARP) de Guiné-Bissau, os projetos de reconstrução da educação de Cabo Verde, Guiné-Bissau, Angola e São Tome e Príncipe.

$\mathrm{Na}$ ambiência do exílio, identificamos seis marcadores no desenvolvimento e na disseminação de sua práxis: a) as influências das experiências com adultos analfabetos no Brasil, sua fundamentação, sistematização e concretização, do final de 1950 em diante; b) a implantação do "Método Paulo Freire", a partir da realidade latino-americana e a es- 
crita da Pedagogia do Oprimido, no Chile, em 1968; c) a atuação acadêmica em Harvard e as apropriações do multiculturalismo nos Estados Unidos; d) o trabalho problematizando questões de identidade cultural, social e política, residindo na Suiça; e) os deslocamentos político-pedagógicos e ideológicos, por meio da militância nos movimentos revolucionários de libertação das colônias portuguesas, a partir de 1975, através das inserções em África; e f) o retorno ao Brasil, com a anistia e o fim do exílio, em 1980.

A família Freire como outros exilados, ${ }^{6}$ em sua maioria, são figuras políticas, e isto thes confere uma identidade que não thes permite a posição de vitimização. Eles não fazem a apologia do exílio, pois isso coadunaria com a lógica acionada pela ditadura que os classificava como criminosos e ameaças à ordem social. Eles se assumem na condição de sujeitos políticos que atuaram na esfera pública, que participaram da luta política no Brasil e depois no mundo (MAZZA; FERREIRA; SPIGOLON, 2015).

As múltiplas rupturas do exílio induzem processos de reconversão identitárias que vincam o viver, pensar, sentir e relacionar, em cenários eivados de provisoriedades.

As reconversões identitárias às quais os exilados tiveram que se submeter, incluindo Paulo Freire, podem ser tomadas como manifestações de processos inacabados de desestruturação/reestruturação, que implicaram rearranjos, melhor ou pior sucedidos, afetando as esferas afetivas, profissionais e jurídicas, entre outras ${ }^{7}$ (SAINT MARTIN, 1995).

6 Trabalhamos com um conceito amplo de exílio, que não se restringe a uma condição jurídica, mas se refere a situações sociais de exclusão, discriminação e restrição de direitos, que compelem indivíduos e grupos a fugir, esconder-se ou viver em lugares que não os de origem ou escolha.

7 Os conceitos de reconversão e identidade referem-se a trabalhos realizados pelos sujeitos ou grupos, mobilizando de modo estratégico os recursos acessados (econômicos, culturais, simbólicos e sociais), as avaliações das oportunidades e as disposições e perspectivas em relação ao futuro. (SAINT MARTIN, 1995)
As influências exercidas pelos cenários nacionais e internacionais, os velhos e novos territórios - externos e internos, do exílio, marcam as escolhas. Paulo Freire passa a compreender que:

[...] tu aprendes a viver a tensão permanente, radicalmente existencial, histórica, entre o contexto de origem, deixado lá, e o contexto novo, de empréstimo, que o exilado começa a ter, na saudade do seu contexto, não um afogamento anestesiador de seu presente, mas uma chama que ilumina o necessário implante na nova realidade. Só na medida em que aprende a viver no novo contexto e a dele sair, mas nele continuando na tensão da contradição dos dois contextos [...] é que the é possivel ter, no contexto de origem, permanente pré-ocupação, jamais uma sombra inibidora do seu presente. $O$ teu corpo veio molhado, como o de qualquer exilado, do contexto de origem, molhado da história, da cultura [...] dos sonhos que nele tinhas, das tuas opções de luta [...] de tuas expectativas, da idealização do próprio contexto. [...] Um caminho, que descobri e outros exilados também descobriram, foi exatamente o de manter o contexto de origem [...] e por outro lado, perseguir certo nivel de inserção afetiva, emocional e intelectual no contexto de empréstimo. (FREIRE; FAUNDEZ, 1985, p. 19-20)

A extensão do exílio de Paulo e sua família, a manutenção e o aprofundamento de suas experiências político-pedagógicas nos induziram aos acervos públicos e privados, tendo em vista perscrutar tempos e espaços, nacionais e internacionais, por meio dos quais detectamos e apresentamos o "Camarada Paulo Freire".

\section{Educação e Revolução: 0 Camarada Paulo Freire}

Há uma unidade indissolúvel entre a revolução e a educação. (FREIRE, 1977, p. 05)

Tornamos público no Brasil uma entrevista concedida por Paulo ao Jornal "Nô Pintcha",

8 Expressão das etnias de Guiné-Bissau que, em crioulo, quer dizer "Empurremos! Vamos em frente". Nome do primeiro jornal do Estado, depois da independência, 
em 1977, ainda no exílio e em uma de suas missões de trabalho em África. Esta fonte documental foi localizada em pesquisa realizada na Biblioteca Pública do Instituto Nacional de Estudos e Pesquisa (INEP), em 2013, Guiné-Bissau, África (SPIGOLON, 2014, p. 288).

Considerando o ineditismo da fonte e a relevância dos temas abordados, optamos por transcrever alguns trechos do texto original:

Jornalista (J): O professor Paulo Freire, é conhecido por todo o nosso povo, de Guiné-Bissau e Cabo Verde, através do seu trabalho e da sua obra. A sua militância [...] no campo da educação [...] para ensinar e aprender com a nossa prática revolucionária, adquirida na luta armada de libertação nacional.

O camarada Paulo Freire já várias vezes em Guiné-Bissau poderá dizer-nos qual o objetivo desta sua viagem [...] e o que já constatou no aspecto da Alfabetização no nosso País?

Paulo Freire (PF): Desde setembro de 1977 que, o grupo do IDAC se encontra a trabalhar na Guiné, a convite do Comissariado da Educação Nacional e, durante todo esse tempo, temos aprendido muito da nossa prática e experiência ensinando um pouco.

A nossa visita está enquadrada na reunião de 1975, quando se definiu a colaboração que iríamos dar ao Governo e, em particular ao Comissariado. 0 objetivo da nossa presença é entrar em contacto com a Comissão Coordenadora dos trabalhos de Alfabetização, com o camarada Comissário Mário Cabral e outros, para estudarmos o que se tem realizado na educação de adultos e, em especial, na alfabetização de adultos, onde o trabalho tem corrido muito bem tanto a nivel das FARP como da população civil.

A minha impressão [...] é a melhor possível, se bem que reconheçamos as dificuldades existentes, mas, salientamos o espírito de militância dos camaradas, assim como, o esforço desenvolvido pelo Comissariado pela Educação no País.

e do primeiro caderno de Educação Popular e Educação de Adultos, elaborado por Paulo e Elza Freire e as equipes dos Países Africanos de Língua Oficial Portuguesa (PALOP).
J: O camarada Freire pode desenvolver um pouco mais o processo de alfabetização nas FARP e população civil?

PF: Nós estudamos em Genebra, tudo o que foi possivel da obra do camarada Amílcar Cabral, que consideramos uma obra mestre, pelo seu espírito crítico e analítico, a sua militância e presença que se sente neste país, como em África e no mundo progressista. Através dos conhecimentos que tínhamos da luta na Guiné, por intermédio das obras de Cabral, nós sabíamos que a alfabetização das FARP seria mais rica e dinâmica, em face da participação e prática na luta contra o colonialismo.

Isso facilitou os militantes das FARP, na aprendizagem da leitura e da escrita. Por isso, [...] nas FARP os camaradas já passam para pós-alfabetização e em Bissau, segundo declarações do camarada das FARP, Júlio de Carvalho, já não há analfabetos e, mesmo no país quase não existe. Nas áreas civis, é um pouco mais dificil, pois a alfabetização não pode ser tão generalizada como nas FARP [...].

Em Có, na Escola Máximo Gorki, onde se faz um bom trabalho de educação revolucionária, eu vi os alfabetizandos a escrever palavras em crioulo, mancanha e português [...] a comissão está a seguir uma orientação fundamental do camarada Amílcar Cabral, que é unir a paciência com a impaciência, ele dizia, 'não devemos correr oportunistamente, mas devemos andar depressa'. O trabalho na Guiné-Bissau com a alfabetização de adultos corresponde a esse equilíbrio entre a paciência e a impaciência. [...]

J: A revolução e a educação são necessárias ao homem, elas interligam-se na obra mais bela da nossa época - a formação do Homem Novo. 0 que pensa o camarada Freire?

PF: A revolução é em si educativa. O camarada Amílcar dizia, 'A luta de libertação é um facto cultural e um fator de cultura'. Há uma unidade indissolúvel entre a revolução e a educação. A revolução propaga [...] na massa popular [...] um processo de formação. Por exemplo: o processo de disciplina, de camaradagem durante a luta, na própria capacidade que o guerrilheiro vai adquirindo para se defender do inimigo, ao mesmo tempo que vai aprendendo um pouco 
de cultura que não conhecia. Por outro lado, estimula a educação, que é um fator essencial na revolução. Há uma ligação íntima entre a revolução e a educação.

E com a chegada ao poder, a revolução que foi educativa no seu processo, com o povo, vai-se servir de uma outra educação totalmente nova e revolucionária, que vai ajudar a criar uma sociedade, com a formação de uma nova mulher e um novo homem. Portanto, a unidade entre a revolução e a educação é tão grande, que quando citamos a primeira estamos a dizer a segunda e, quando falamos em educação revolucionária logo é a revolução [...]

J: Porém, antes de terminar, o camarada Paulo Freire referiu-se a recente viagem efectuada há dias, a Angola e a São Tomé.

PF: Nesses países, os problemas são os mesmos que na Guiné-Bissau, mas com características diferentes e como tal, não podem ser resolvidos da mesma maneira. [...] todos os cinco países irmãos, enfrentam problemas similares, como superar o sistema educacional herdado e criar um novo sistema. Estão envolvidos nessa luta que é a continuação da luta de libertação e, até seria uma contradição se algum desses países continuasse a preservar o sistema educacional colonialista. Por outro lado, não é possivel fazer essa superação por decreto [...]. Em Angola, estamos a trabalhar, sobretudo ao nivel de pós-alfabetização e na cultura geral e, em São Tomé e Príncipe, estamos a trabalhar na capacitação de quadros para alfabetização. Estão muito curiosos com o que se passa na Guiné, os contatos vão aumentando e o camarada Mário Cabral pensa [...] realizar um encontro dos cinco países, para analisar o passado a fim de se chegar a uma conclusão, no aumento das dinâmicas dos esforços no campo educacional. (FREIRE, 1977, p. 05)

\section{(In)Conclusões: Nô djunta mô9}

Se nada ficar dessas páginas, algo, pelo menos, esperamos que permaneça: nossa confiança no

9 Expressão das etnias de Cabo Verde que em crioulo quer dizer "todos de mãos dadas" e que nomeou a Campanha e o Manual de Alfabetização para Adultos elaborado por Paulo e Elza Freire e as equipes dos PALOP. povo. Nossa fé nos homens e na criação de um mundo que seja menos dificil de amar. (FREIRE, 1972, p. 184)

A abordagem (auto)biográfica do exílio de Paulo Freire nos conduziu a tempos e espaços nos quais a Educação se vinculou a experiências teóricas e práticas de Revolução. Em um momento de retrocessos na implementação de direitos constitucionais, aprofundamento da inflexão liberal conservadora, nas sociedades nacionais e no cenário internacional, a adesão de setores populares a propostas obscurantistas, tais como: Escola Sem Partido; reforma do Ensino Médio, minimizando a obrigatoriedade das disciplinas de humanidades; revisão da Base Nacional Curricular Comum, tendo em vista subsumir os processos de ensino dos professores e o aprendizado dos alunos às exigências do Programa Internacional de Avalição dos Estudantes (PISA); trazer a relação entre Educação e Revolução tal como urdida por Paulo Freire é uma forma de luta e resistência.

No Recife, Paulo Freire forma-se em Direito, em 1946, e por influência de Elza é levado para a Educação. Como educador, atua junto a grupos de Cultura Popular e de Alfabetização de Adultos, no Nordeste, alcança notoriedade e compõe o Governo do presidente João Goulart. Em 1964, é acometido pelo golpe que o inquire e aprisiona, acossando-o e a sua família ao exílio.

A condição de exilado político qualifica os trabalhos de Paulo, como revolucionários, e o exílio empurra os Freires para além dos paroquialismos regionais e nacionais, identificando-os como partícipes de movimentos de esquerda.

A sucessão de governos ditatoriais que se estende pela América do Sul força Paulo Freire e sua família a deslocamentos sucessivos, inicialmente não previstos, que os rotulam cada vez mais como perseguidos políticos de esquerda. 
As fontes reunidas, incluindo as narrativas (auto)biográficas, sustentam que a inserção político-pedagógica de Paulo Freire no Brasil o aproximou, no exílio, dos grupos revolucionários que circularam pelas Américas, Europa e África.

Ao descrever percursos, investigar processos e escavar fontes, colocamo-nos em oposição às ditaduras, no Brasil e no mundo, e a favor de uma Educação cuja dimensão humana se faça emancipatória e conscientizadora, tal como esboçada na vida e obra de Paulo Freire. No exílio, permaneceu vinculado a grupos, instituições e governos que se ocupavam de projetos, programas e ações, no campo da cultura, educação popular e educação de Adultos. As mobilidades geográficas recobrem Brasil, Bolívia, Chile, Estados Unidos, Suiça e culminam com as inserções e intervenções político-pedagógicas nos PALOP.

$\mathrm{Na}$ condição de exilado político, ele, ao lado de Elza e família, sistematizou e publicizou muitas das obras que o tornaram conhecido mundo afora.

Paulo e Elza Freire passam a integrar o grupo de camaradas composto por: Luís e Mário Cabral, Augusta Henriques, em Guiné-Bissau; Artur Carlos M. P. dos Santos - Pepetela e Agostinho Neto, em Angola; Aristides Pereira, Carlos Reis e Lilica Boal, em Cabo Verde; Manuel Pinto da Costa e Maria Amorim, em São Tomé e Príncipe; os quais, através da Educação, lutavam para fortalecer os movimentos revolucionários e os governos de libertação nacional.

Os camaradas têm em comum o ideal de que, por meio da educação para todos, se consolidaria a independência dos novos países e a participação democrática da população na vida nacional.

O exilado político brasileiro, em tempos e espaços de educação, exílio e revolução, converte-se no Camarada Paulo Freire e ante o debate contemporâneo é referência na memória daqueles que lutam pela extinção do analfabetismo.

Não posso ser professor a favor simplesmente do homem ou da humanidade, frase de uma vaguidade demasiado contrastante com a concretude da prática educativa. Sou professor a favor da decência contra o despudor, a favor da liberdade contra o autoritarismo, da autoridade contra a licenciosidade, da democracia contra a ditadura de direita ou de esquerda. Sou professor a favor da luta constante contra qualquer forma de discriminação, contra a dominação econômica dos indivíduos ou das classes sociais. (FREIRE, 2006, p. 102-103)

Nesse obscuro momento pelo qual passa o país, movimentos ultraconservadores intentaram retirar de Paulo Freire o título de "Patrono da Educação Brasileira", concedido pela Lei 12.612/2012. Recobramos o percurso político-pedagógico de Paulo Freire durante o exílio, tendo em vista compreender que a história social e educacional se realiza por meio de movimentos, de abertura e fechamento, resistências e constrangimentos, emancipações e embrutecimentos. No bojo dessas conjunções, o então educador alçou a condição de camarada.

\section{Referências}

BEISIEGEL, Celso de Rui. Estado de educação popular. São Paulo: Pioneira, 1974.

BEISIEGEL, Celso de Rui. Política e educação popular. São Paulo: Ática, 1982.

BOITO JR, Armando; BERRINGER, Tatiana. Brasil: classes sociais, neodesenvolvimentismo e política externa nos governos Lula e Dilma. Rev. Sociol. Polit., v. 21, n. 47, p. 31-38, 2013.

BRUNEAU, Michel. Pour une approche de la territorialité internationale: les notions de disapora et de communité transnationale. In: ARAB, Chadia et al. Les circulations transnationales. Lire les turbulences migratoires contemporaines. Paris: Armand Colin, 2009. p. 29-42. 
BRUNER, Jerome. Atos de significação. Porto Alegre: Artmed, 1997.

CHAUÍ, Marilena. Conformismo e resistência. São Paulo: Brasiliense, 1985.

CHARTIER, Roger. A visão do historiador modernista. In: FERREIRA, Marieta de M.; AMADO, Janaina. (Orgs.). Usos e abusos da história oral. Rio de Janeiro: Editora da Fundação Getúlio Vargas, 1996. p. 215-218.

CORTES, Geneviève; FARET, Laurent. La circulation migratoire dans “l'ordre des mobilités. In: ARAB, Chadia et al. Les circulations transnationales. Lire les turbulences migratoires contemporaines. Paris: Armand Colin, 2009. p. 7-19.

COSTA, Albertina de Oliveira et al. (Orgs.). Memórias das mulheres do exílio. Rio de Janeiro: Paz e Terra, 1980.

CRUIKSHANK, Julie. Tradição oral e história oral: revendo algumas questões. In: FERREIRA, Marieta de M.; AMADO, Janaina (Orgs.). Usos e abusos da história oral. Rio de Janeiro: Editora da Fundação Getúlio Vargas, 1996. p. 149-166.

DAVIS, Kathy; PRADILLA, Victoria. La biografia como metodologia critica. Historia, Antropologia y Fuentes Orales, Barcelona, Memoria Rerum, n. 30, p. 153160, 2003.

DELORY-MOMBERGER, Christine. A pesquisa biográfica: projeto epistemológico e perspectivas metodológicas. In: ABRAHÃO, Maria Helena M. B.; PASSEGGI, Maria da Conceição. (Orgs). Dimensões metodológicas da pesquisa (auto)biográfica: Tomo I. Natal: EDUFRN; Porto Alegre: EDIPUCRS; Salvador: EDUNEB, 2012. p. 71-93.

DEMARTINI, Zeila de Brito Fabri. Relatos orais, documentos escritos e imagens: fontes complementares na pesquisa sobre imigração. In: ROCHA-TRINDADE, Maria Beatriz; CAMPOS, Maria Christina Siqueira de Souza. (Orgs.). História, memória e imagens nas migrações: abordagens metodológicas. Oeiras: Portugal: Celta Editora, 2005. p. 99-134.

DREIFUSS, René Armand. 1964: a conquista do Estado: ação política, poder e golpe de classe. Petrópolis, RJ: Vozes, 2008.
DUBAR, Claude. A crise das identidades: a interpretação de uma mutação. São Paulo: EDUSP, 2009.

FÁVERO, Osmar. Cultura popular, educação popular, memória dos anos 60. Rio de Janeiro: Graal, 1983.

FERNANDES, Florestan. A revolução burguesa no Brasil: ensaio de interpretação sociológica. Rio de Janeiro: Zahar Editores, 1975.

FREIRE, Paulo. Educação como prática da liberdade. Rio de Janeiro: Paz e Terra, 1967.

FREIRE, Paulo. Pedagogia do oprimido. Porto: Afrontamento, 1972.

FREIRE, Paulo. Há uma unidade indissolúvel entre a revolução e a educação. Entrevista. In: Jornal “Nô Pintcha", Bissau, Guiné-Bissau, ed. 09 de abril, p. 05, 1977.

FREIRE, Paulo. Pedagogia da esperança. São Paulo: Paz e Terra, 1992.

FREIRE, Paulo. Pedagogia da indignação: cartas pedagógicas e outros escritos. São Paulo: Editora Unesp, 2000.

FREIRE, Paulo. Pedagogia da autonomia: saberes necessários à prática educativa. São Paulo: Paz e Terra, 2006.

FREIRE, Paulo; BETTO, Frei. Essa escola chamada vida: depoimentos ao repórter Ricardo Kotscho. São Paulo: Editora Ática, 2000.

FREIRE, Paulo; FAUNDEZ, Antônio. Por uma pedagogia da pergunta. São Paulo: Paz e Terra, 1985.

FREIRE, Paulo; GUIMARÃES, Sérgio. Aprendendo com a própria história. V. I. 2. ed. São Paulo: Paz e Terra, 2001.

FREIRE, Paulo; GUIMARÃES, Sérgio. Aprendendo com a própria história. V. II. 2. ed. São Paulo: Paz e Terra, 2002.

FREIRE, Paulo; OLIVEIRA, Rosiska Miguel Darcy de.; CECCON, Claudius. Vivendo e aprendendo: experiências do IDAC em educação popular. São Paulo: Brasiliense, 1980.

GALEANO, Eduardo. As palavras andantes. Porto 
Alegre: L\&PM, 2007.

HALBWACHS, Maurice. A memória coletiva. São Paulo: Editora Centauro, 2015.

HALL, Stuart. Da diáspora: identidades e mediações culturais. Belo Horizonte: Editora da UFMG, 2009.

JULIÃO, Francisco. Esperança é meu signo. In: CAVALCANTI, Pedro Celso Uchôa; RAMOS, Jovelino. (Coords.). Memórias do Exílio, Brasil 1964/19?? Volume 1 - De muitos caminhos. São Paulo: Editora e Livraria Livramento Ltda., 1978. p. 287-299.

LARROSA, Jorge. La experiencia de la lectura. Estudios sobre literatura y formación. Barcelona: Laertes S. A. Ediciones, 1996.

LEFEBVRE, Henri. Espaço e política. Belo Horizonte: Editora da UFMG, 2008.

MAZZA, Débora. A produção sociológica de Florestan Fernandes e a problemática educacional: uma leitura (1941-1964). Taubaté: Cabral Editora e Livraria Universitária, 2003.

MAZZA, Débora; FERREIRA, Márcia dos Santos; SPIGOLON, Nima Imaculada. O golpe de 1964 no Brasil: memórias de mulheres sobre o exílio. Cadernos CERU, São Paulo, FFLCH/ USP, v. 26, n. 1, p. 167-183, 2015.

NÓVOA, Antônio. Firmar a posição como professor, afirmar a profissão docente. Cadernos de Pesquisa, v. 47, n. 166, p. 1106-1133, out./dez. 2017.

PAIVA, Vanilda. Educação popular e educação de adultos, contribuição à história da educação brasileira. São Paulo: Loyola, 1973.

PEPETELA [PESTANA dos Santos, Artur Carlos Maurício]. A geração da utopia. Lisboa: Dom Quixote, 1997.

ROLLEMBERG, Denise. Exílio entre raízes e radares. Rio de Janeiro: Editora Record, 1999.

ROSAS, Paulo. Papéis avulsos sobre Paulo Freire, 1. Recife: Centro Paulo Freire - Estudos e Pesquisas: Editora Universitária da UFPE, 2003.

SAID, Edward. Reflexões sobre o exílio e outros ensaios. São Paulo: Cia. das Letras, 2003.
SAINT MARTIN, Monique de. Reconversões e reestruturações das elites: o caso da aristocracia em França. Análise Social, Revista do Instituto de Ciências Sociais da Universidade de Lisboa, v. XXX (50.), n. 134, p. 1023-1039, 1995.

SPIGOLON, Nima Imaculada. Pedagogia da convivência: Elza Freire - uma vida que faz educação. Jundiaí: Paco Editorial, 2016

SPIGOLON, Nima Imaculada. As noites da ditadura e os dias de utopia - o exílio, a educação e os percursos de Elza Freire nos anos de 1964 a 1979. 2014. 506 f. Tese (Doutorado em Educação) - Faculdade de Educação, Universidade Estadual de Campinas, Campinas, 2014.

SOUZA, Elizeu Clementino de.; CASTAÑEDA, José Antonio Serrano; MORALES, Juan Mario Ramos. Autobiografía y educación: tradiciones, diálogos y metodologías. Revista mexicana de investigación educativa (RMIE), México, v. 19, n. 62, p. 683-694, jul./ sep. 2014.

TOLEDO, Caio Navarro de. 0 governo Goulart e o golpe de 64. São Paulo: Brasiliense, 1983.

WEFFORT, Francisco Correia. 0 populismo na política brasileira. Rio de Janeiro: Paz e Terra, 1978.

YANKELEVICH, Pablo. Introducción. In: YANKELEVICH, Pablo; JENSEN, Silvina. (Orgs.). Exilios: destinos y experiências bajo la dictadura militar. Buenos Aires: Libros Del Zorzal, 2007. p. 09-20.

VÁZQUEZ, Adolfo Sánchez. Entre a realidade e a utopia: ensaios sobre política, moral e socialismo. Rio de Janeiro: Civilização Brasileira, 2001.

VIÑÃO, Antonio. A modo de prólogo: refugios del yo, refugio de otros. In: MIGNOT, Ana Crystina V.; BASTOS, Maria Helena Câmara; CUNHA, Maria Teresa Santos. (Orgs.). Refúgios do eu: educação, história e escrita autobiográfica. Florianópolis: Mulheres, 2000. p. 9-15.

Recebido em: 15.02.2018

Aprovado em: 20.03.2018 
Débora Mazza é Pós-doc em Sociologias Especiais (EHESS/Paris e GTM/Paris). Doutorado em Ciências Sociais (IFCH/ UNICAMP). Docente da Faculdade de Educação, DECISE-UNICAMP, credenciada no Programa de Pós-Graduação em Educação e Diretora Associada FE (2016/2020). Grupo de Pesquisas em Políticas, Educação e Sociedade (GPPES). e-mail: dmazza@unicamp.br

Universidade Estadual de Campinas (UNICAMP). Faculdade de Educação. Rua Bertrand Russel, 801 Cidade Universitária "Zeferino Vaz". CEP 13.083-865 - Campinas/SP. Telefones: (19) 99126-6806 e/ou (19) 3326-6806.

Nima I. Spigolon é Doutorado em Educação (FE/UNICAMP). Docente da Faculdade de Educação, DEPASE-UNICAMP e do Programa de Pós-Graduação em Educação. Grupo de Estudos e Pesquisas em Educação de Jovens e Adultos (GEPEJA) e Grupo de Pesquisas em Políticas, Educação e Sociedade (GPPES). e-mail: nima@unicamp.br

Universidade Estadual de Campinas (UNICAMP). Faculdade de Educação. Rua Bertrand Russel, 801 Cidade Universitária “Zeferino Vaz". CEP 13.083-865 - Campinas/SP. Telefones: (19) 99662-1726 e/ou (19) 3324-3069. 